\title{
http://dx.doi.org/10.35381/racji.v5i1.633
}

\section{Derechos del debido proceso en los sumarios administrativos en la Ley Orgánica de Educación Intercultural}

\section{Due process rights in administrative summaries in the Organic Law of Intercultural Education}

\author{
Luis Miguel López-Shishingo \\ luis.lopez@psg.ucacue.edu.ec \\ Universidad Católica de Cuenca, Cuenca \\ Ecuador \\ https://orcid.org/0000-0002-2829-2274 \\ Cecilia Ivonne Narváez-Zurita \\ inarvaez@ucacue.edu.ec \\ Universidad Católica de Cuenca, Cuenca \\ Ecuador \\ https://orcid.org/0000-0002-7437-9880 \\ José Luis Vázquez-Calle \\ jlvazquezc@ucacue.edu.ec \\ Universidad Católica de Cuenca, Cuenca \\ Ecuador \\ https://orcid.org/0000-0003-4980-6403 \\ Juan Carlos Erazo-Álvarez \\ jcerazo@ucacue.edu.ec \\ Universidad Católica de Cuenca, Cuenca \\ Ecuador \\ https://orcid.org/0000-0001-6480-2270
}

Recibido: 13 de noviembre de 2019

Aprobado: 16 de diciembre de 2019

\section{RESUMEN}

El presente artículo torna su interés en el análisis del debido proceso como una institución jurídica que vela por el cumplimiento de las garantías constitucionales de las personas inmersas en un sumario administrativo, dentro de este proceso contemplado en el reglamento general a la Ley Orgánica de Educación Intercultural, en sus fases de acciones previas y en la etapa de prueba, no se determina de forma precisa cuales son las acciones que las partes procesales tienen que ejecutar para 
solicitar, evacuar y contradecir las pruebas presentadas. Se hace énfasis en la importancia de contar con un juez natural en este tipo de procedimientos, pues según la norma que lo contempla señala que la JDRC es un órgano integrado por los mismos funcionarios del nivel distrital de educación, el Ministerio de Educación y su normativa no estaría garantizando el derecho de los docentes a ser juzgados por un juez competente.

Descriptores: Debido proceso; vulneración; Ley Orgánica de Educación Intercultural; reglamento general, sumarios administrativos.

\begin{abstract}
This article turns its interest in the analysis of the due process as a legal institution that watches over the fulfillment of the constitutional guarantees of the people immersed in an administrative summary, within this process contemplated in the general regulation to the Organic Law of Intercultural Education, in its phases of previous actions and in the trial stage, it is not determined precisely what are the actions that the procedural parties have to execute to request, evacuate and contradict the evidence presented. Emphasis is placed on the importance of having a natural judge in this type of procedure, since according to the norm that contemplates it, it indicates that the JDRC is an organ integrated by the same officials of the district level of education, the Ministry of Education and its regulations I would not be guaranteeing the right of teachers to be judged by a competent judge.
\end{abstract}

Descriptors: Due process; infringement; Organic Law of Intercultural Education; administrative summaries.

\title{
INTRODUCCIÓN
}

El Derecho desempeña un rol fundamental para regular todas las actividades de las personas dentro de una sociedad, ya que los individuos que conviven cotidianamente se encuentran relacionados de forma directa con esta ciencia, por lo que no se podría entender la concepción del Derecho sin la existencia de las personas, en tal virtud el Derecho desde una conceptualización general consiste en un mecanismo imperativo y necesario que permite el normal desenvolvimiento de las diligencias generadas por todas las personas, manteniendo como una de sus finalidades alcanzar una fraternidad y armonía entre los individuos que conforman un Estado constitucional de justicia e igualdad, permitiendo inclusive la subsanación y reparación de cualquier derecho que haya sido vulnerado (Pérez y Carrasco, 2007). 
Una de las ramas del Derecho que se debe abordar dentro del presente trabajo es el Derecho Constitucional, ya que el mismo garantiza el goce de los derechos individuales y colectivos y defiende al ser humano desde el un punto de vista igualitario, su estudio se centra en las personas y derechos fundamentales, además se encuentra siempre vigilante que el Estado y sus poderes garanticen que el ciudadano pueda acceder a la justicia mediante el respeto de todos sus derechos (Guzmán Chávez, 2019).

En el Ecuador el Derecho Constitucional cobra mayor realcé a partir de la Constitución del año 2008 donde se desarrollan derechos constitucionales, como por ejemplo dentro del ámbito ecónomico el aparataje estatal mantiene como uno sus objetivos el ser un Estado equitativo donde las riquezas se distribuyan en partes iguales, en lo referente a los derechos ambientales se considera a la naturaleza por primera vez como un sujeto de derecho, así también en el ámbito social aparecen con mayor claridad las garantías de acceder gratuitamente al derecho a la salud, al trabajo, a la educación, entre otros derechos constitucionales (Grijalva A. , 2012), situación que sin duda favorece para que todas las personas tengan acceso a ejercitar sus derechos constitucionales.

De lo antes manifestado, el Derecho Constitucional se establece como una fuente donde surgen varios derechos que a la vez se van sistematizando para generar mecanismos de prevención y protección de los derechos de rango constitucional, siendo el derecho al debido proceso una institución jurídica por la cual se permite a las partes que intervienen dentro de un proceso mantener una comunicación directa con su juzgador, así también, conservan la facultad de presentar pruebas pertinentes a su favor y contradecir las pruebas que fuesen desfavorables, estas acciones permiten al juez tener la certeza para dictar un veredicto dentro del caso puesto en su conocimiento (Ibidem).

En este punto, el debido proceso consiste en una institución jurídica que debe estar presente en todo procedimiento, es así que, en el artículo 1 de la Ley Orgánica de Educación Intercultural señala como uno de sus múltiples objetivos el garantizar el cumplimiento de los derechos y obligaciones de los docentes, estudiantes y padres de familia (Ley Orgánica de Educación Intercultural, 2011). Así también, la referida 
ley se encarga de regular las acciones y relaciones entre estos actores de la comunidad educativa, otro aspecto a considerar es que los docentes que forman parte del Ministerio de Educación al encontrarse regulados por una ley orgánica de carácter especial, deben cumplir con los derechos y obligaciones contemplados en el capítulo cuarto en los artículos 10 y 11 de la ley en mención, siendo uno de sus derechos el ejercer el debido proceso en el caso de haber sido acusados de contravenir normas constitucionales o normas infra constitucionales.

El debido proceso constituye un factor importante en la situación legal de los estudiantes y docentes, más cuando estos últimos en ocasiones se encuentran inmersos en procesos de sumarios administrativos, los mismos que se encuentran regulados y contemplados en el reglamento general a la Ley Orgánica de Educación Intercultural, por consiguiente, la presente investigación tiene por objetivo determinar qué ocurre con las garantías del debido proceso en lo que respecta al derecho a mantener un juez natural y la correcta evacuación de la prueba dentro de los procesos de sumarios administrativos de los docentes del Ministerio de Educación.

Así también, es necesario abordar la problemática relacionada con algunos aspectos procesales importantes que garanticen la correcta aplicación del debido proceso específicamente al momento de la incorporación de pruebas por parte de la entidad administrativa dentro del proceso de sumario administrativo, de igual forma se puede denotar una carencia de un juez natural para resolver los sumarios administrativos, pues el cuerpo colegiado competente denominado Junta de Resolución de Conflictos no constituye un ente independiente por formar parte integral de la entidad administrativa, la misma que sustancia el proceso de principio a fin.

\section{El debido proceso como un conjunto de garantías, principios y derechos presentes en todo procedimiento sancionador}

El origen del debido proceso se encuentra en la Carta Magna del año 1215 suscrita por el rey Juan Sin Tierra de Inglaterra, donde los varones ingleses cansados de los múltiples atropellos del rey, consiguen mediante varios acuerdos la eliminación de estas prácticas de ejecuciones y muerte hacia ellos, sin que antes se les brinde un 
proceso legal y justo (Rodríguez, 2010). Posterior a estos acontecimientos en el año de 1345 aparece en Inglaterra el Estatuto 28 del rey Eduardo III quien estipula al debido proceso como una ley donde se escuchaba a las partes antes de emitir un veredicto. De modo similar en los Estados Unidos de Norte América, esta institución jurídica se desarrolla en la quinta enmienda de la Constitución del año 1791, con la que se crea un proceso previo a establecer cualquier tipo de responsabilidad legal a las personas (Espinoza, 2000).

Como consecuencia de ello, en Latinoamérica el concepto del debido proceso surge con base en el artículo $287^{1}$ de la Constitución de Cádiz, donde se instauran juicios razonables y justos, con lo cual varios años después estas prácticas fueron replicadas por varias codificaciones de los países latinoamericanos que han aceptado estos derechos fundamentales encontrándose presentes en casi todas las legislaciones de la región (Rodríguez, 2010) Constituyéndose como requisito sine qua non que garantice los derechos a través de la existencia de un mecanismo de justicia al cual pueda acceder cualquier persona.

Ruocco (2013) afirma que el debido proceso mantiene dos aristas: una formal y otro material. En un sentido formal, los derechos van concatenados dentro de un procedimiento con la finalidad de establecer un juicio justo, por ejemplo el derecho a ser escuchado, derecho a la defensa, derecho a la contradicción, derecho a ser juzgado por una autoridad imparcial, derecho a reproducir prueba a favor, entre otros; por otra parte, se entiende al debido proceso en un sentido material, como el conjunto de derechos y principios que contienen un carácter fundamental de razonabilidad de las normas en beneficio directo de los seres humanos.

Es así que, se comprende al debido proceso como una institución jurídica por la cual se permite a las partes que intervienen dentro de un proceso mantener una comunicación directa con su juzgador, en donde se presentan pruebas pertinentes a su favor para contrarrestar las pruebas que fuesen desfavorables, acciones que sin

Constitución de Cádiz Art. 287. Ningún español podrá ser preso sin que preceda información sumaria del hecho por el que merezca, según la ley, ser castigado con pena corporal, y asimismo un mandamiento del juez por escrito, que se le notificará en el acto mismo de la prisión 
duda permitirán al juez mantener la certeza de las cosas previo a dictar su veredicto dentro del caso puesto en su conocimiento (Talavera, 2009).

Así también, Velásquez (2017) advierte que el debido proceso se entiende como un conjunto de principios procesales, que de forma obligatoria deberán considerarse en todo tipo de procedimientos legales que se encuentren ventilados por cualquier autoridad encargada de resolver. Por su parte, González (2006) otorga una definición más amplia sobre el debido proceso, al incorporar elementos como el derecho a la defensa, derecho a la garantía de audiencia y motivación de las sentencias dictadas por autoridad competente, los mismos que constituyen derechos fundamentales y principios que conforman en su integridad el derecho del debido proceso, estableciendo de esta forma un proceso justo y equitativo para las partes procesales.

En este marco de referencia, resulta esencial que los organismos internacionales de derechos humanos mantengan dentro de sus instrumentos internacionales al debido proceso como norma fundamental con la cual se asegure el cumplimiento de una serie de derechos que se encuentran inmersos dentro de esta entidad jurídica. Es así que, durante su desarrollo se ha ido perfeccionando su concepción a tal punto de existir una gran cantidad de jurisprudencia y de opiniones consultivas emitidas de las altas cortes internacionales al respeto del tema en mención (Bonilla, 2015). Atendiendo a estas consideraciones, la Corte Interamericana de Derechos Humanos (Corte IDH) y la Comisión Interamericana de Derechos Humanos (CIDH) mediante instrumentos jurídicos han ido desarrollando una línea de conceptualización del debido proceso que podría catalogarse como estándar internacional, estos documentos tienen su origen en los informes estatales, opiniones consultivas, casos reales puestos en conocimiento de la $\mathrm{CIDH}$ y de sobre manera las múltiples sentencias emitidas por la Corte IDH (Blanco, 2012).

En este sentido, los ordenamientos jurídicos internos de cada Estado de forma necesaria y obligatoria mantendrán armonía con lo establecido y dispuesto en los instrumentos internacionales antes indicados siempre y cuando contengan normas más favorables a los derechos humanos, ya que con ello se garantizará el respeto y cumplimiento de lo dispuesto por las altas cortes internacionales (Nogueira, 2003). 
Sin duda, algo que resalta dentro de la jurisprudencia de la ${ }^{2}$ Corte $\mathrm{DIH}$, es que se constituye un mandato de carácter obligatorio para los Estados el realizar una investigación de los casos en concreto, que garantice un correcto proceso, se investigue la verdad de los hechos y se juzgue en base a la valoración de las pruebas presentadas de manera legal, así también que la autoridad competente sea un ente imparcial que haga prevalecer la justicia, y se proceda a sancionar a las personas naturales o jurídicas que hayan vulnerado los derechos inherentes a los seres humanos (Rojas, 2011). De la revisión del caso Nogueira de Carvalho y otro vs. Brasil, se deja sentado que la Corte IDH no constituye una cuarta instancia donde se tenga que valorar nueva prueba o realizar un examen de la misma o de los hechos, ya que su accionar recae en constatar que en los procedimientos domésticos no se hayan inobservado los derechos y principios del debido proceso (Blanco, 2012).

Atendiendo a las consideraciones expuestas, el artículo 76 de la Constitución de la República del Ecuador señala al debido proceso como un conjunto de derechos y principios que garantizan la protección de los derechos humanos, por lo que al efectivizarse este presupuesto y considerándose que se trata de una norma constitucional de jerarquía superior, el debido proceso se convierte en mandato de obligatorio cumplimiento en todos los ámbitos y procedimientos, incluidos los procedimientos administrativos (Asamblea Constituyente, 2008) En el debido proceso se encuentran incorporados los siguientes principios:

Principio legalidad.- Mantiene sus raíces en el vocablo latín Nullun crimen, nulla poene, sine lege, mismo que traducido significa que primero debe existir una norma jurídica tipificada que describa una conducta prohibida y en consecuencia establecer una pena para castigar si se llegare establecer la culpabilidad (Sarango, 2008).

Principio de igualdad. - Este principio está compuesto por la igualdad formal y la igualdad material. La igualdad formal versa sobre la aplicabilidad de las leyes en forma igualitaria a todas las personas sin distinción de raza, sexo, o condición social;

\footnotetext{
${ }^{2}$ Corte Interamericana de Derechos Humanos= Corte IDH

Comisión Interamericana de Derechos Humanos $=\mathrm{CDIH}$
} 
sin embargo, dentro de un Estado social de derechos es necesario que se reinterprete este concepto considerando aspectos económicos y sociales de los individuos al instante que se aplica la ley, en consecuencia no es suficiente que los gobiernos dicten normas jurídicas a favor de los derechos, ya que se requiere además la implementación de diferentes mecanismos para lograr la consolidación de una verdadera igual de todos los ciudadanos (Cardona, 1994). El principio de igual que consta en el Art. 11 numeral 2 de la Constitución de la República mantiene relación con el principio de contradicción, el mismo consiste en la dualidad que tienen el autor y demandado dentro de un proceso legal para que sean considerados de forma equitativa por el juzgador que deberá dictar su resolución en base a las pretensiones, alegaciones y pruebas que las partes hayan presentado dentro del proceso.

En el principio de contradicción. - Es muy imperativo indicar que resulta prohibido el incorporar al proceso pruebas obtenidas de forma ilegal, ilegitima y dudosa, en el sentido, de que no sea puesto en conocimiento de la otra parte para que esta se pronuncie sobre la misma (Sanabria, 2017).

En este orden de ideas, se debe precisar que el debido proceso se encuentra concatenado con una serie de normas como el derecho a obtener una resolución motivada, derecho a la legítima defensa, el derecho a ser juzgado por un juez imparcial y competente. En este sentido, la Corte Constitucional del Ecuador ha señalado que, el derecho a la defensa actúa dentro del proceso de forma conjunta con las demás garantías, por ello este derecho no puede ser puesto en el mismo plano que las otras garantías procesales, sino que su inviolabilidad es la garantía crucial con la que cuenta el ciudadano, ya que es la única que permite que las demás garantías tengan vigencia concreta dentro de cualquier tipo de proceso; es así que, si el derecho a la defensa no se cumple de forma pertinente, como consecuencia de ello se deberá declarar la nulidad absoluta de todo proceso (Secretaría Técnica Jurisdiccional, 2016).

Así también, el derecho a la defensa tiene como finalidad que los operadores de justicia ya sean estos judiciales o administrativos no extralimiten sus facultades y en base de ello vulneren los derechos que las partes procesales, de esta manera 
deberán asegurar un procedimiento imparcial donde siempre prevalecerá la verdad y la justicia para que de esta forma se pueda llegar a obtener una resolución que garantice la Tutela Judicial Efectiva (Benavides, 2017).

\section{Los sumarios administrativos en la Ley Orgánica de Educación Intercultural (LOEI) y su Reglamento General (RGLOEI)}

Los sumarios administrativos constituyen un procedimiento administrativo disciplinario que mantiene su génesis como una rama del Derecho Administrativo, donde el Estado cumple un rol fundamental de mantener las relaciones laborales en orden con referencia a sus empleados, siendo estos en calidad de servidores públicos los llamados a cumplir las normas emanadas de forma expresa por los distintos organismos públicos, ya que en caso de no hacerlo las entidades del sector estatal podrán ejercitar su potestad sancionadora iniciando un procedimiento para determinar el grado de responsabilidad por cualquier tipo de acción u omisión que el servidor haya cometido en el cumplimiento de sus obligaciones (Gómez, 2015).

De manera similar para Pertile (2005), el sumario administrativo consiste en una herramienta procedimental compuesta por normas previas establecidas por el órgano de administración pública, en el cual se va a determinar la existencia o no de responsabilidades a los agentes estatales del incumplimiento de las actividades que se les asignada de manera anticipada, dentro de este procedimiento administrativo también la administración pública conocerá, investigara y determinara la existencia de alguna infracción administrativa previo a imponer su potestad sancionadora.

Bajo este mismo contexto, el sumario administrativo se encuentra conceptualizado dentro de la Ley Orgánica de Servicio Público (LOSEP), la misma que señala que "el sumario administrativo es un procedimiento oral, y motivado por el cual el Ministerio del Trabajo determinará el cometimiento o no de las faltas administrativas graves establecidas en la ley referida, por parte de un servidor público" (Art. 44). En tal virtud, se deberá entender que la norma pre citada es considerada como norma subsidiaria a la Ley Orgánica de Educación Intercultural y a su reglamento general, por lo que es oportuno manifestar de manera precisa que los docentes deben 
cumplir todos los derechos de servidores públicos contemplados en la Constitución de la Republica y en la Ley Orgánica de Servicio Público.

De los conceptos expuestos se comprende al sumario administrativo como un procedimiento sistemático compuesto por varias etapas que se instauran en contra de los servidores públicos que hayan incurrido de manera presunta en alguna de las prohibiciones que mantienen, o por omisiones del cumplimiento de sus atribuciones legales emanadas de forma previa y clara por el Estado, de ello también es importante mencionar que los sumarios administrativos se inician por única vez cuando el servidor público incurra un algunas de las prohibiciones consideradas como faltas graves, de este modo existen otros procedimientos más simples que se dedican a sancionar las faltas leves de los servidores públicos (Bedón, 2016).

Sin duda, el sumario administrativo para docentes del Ministerio de Educación se enmarca dentro de las conceptualizaciones de los procesos administrativos disciplinarios antes expuestos, ya que el mismo constituye un mecanismo sistematizado de normas procesales que contemplan cada una de sus fases estipuladas con antelación en el reglamento general a la LOEI. En este escenario, el sumario administrativo tiene por finalidad ofrecer al ente sancionador elementos de convención necesarios para determinar responsabilidades administrativas, para lo cual se establecen varias sanciones como las suspensiones temporales de hasta máximo de 70 días o la destitución del docente, según las normas administrativas infringidas por este. Estas sanciones se encuentran previstas dentro de la (Ley Orgánica de Educación Intercultural , 2011, Art. 133).

Con relación a las fases del procedimiento del sumario administrativo contemplado en la LOEI y su reglamento general estas mantienen similitud con las etapas del procedimiento administrativo sancionador que constan tipificadas en el Código Orgánico Administrativo (COA) en sus artículos 175, 248, 249, 250, 251, 252, 253, 254, 255, 256, 257, 258,259, 260. Debiendo indicar que el referido Código, promulgado en el año 2017, tiene la finalidad de unificar los múltiples procedimientos administrativos existentes en todos los organismos del sector público y además complementar algunos aspectos que no se determinan en otros procedimientos administrativos. 
Es así que, los procedimientos administrativos sancionadores en forma general previo a dar inicio deberán ejecutar una fase de indagación de los hechos, la misma que estará bajo la responsabilidad de la parte administrativa y podrá realizarse a petición de los interesados o de oficio, dentro de esta fase se investigara los hechos acontecidos para que la entidad pública tenga pleno conocimiento del caso en concreto y de este modo pueda determinar si es pertinente iniciar o no con el procedimiento sancionador.

En efecto el artículo 346 del reglamento general a la LOEI señala dos preceptos legales básicos presentes en la fase de indagación, siendo el primero la obligación que mantiene el organismo público de respetar y hacer cumplir el debido proceso en todas las fases del sumario administrativo iniciado en contra de los docentes y el segundo con relación a la disposición de iniciar con una fase de acciones previas, donde la Junta Distrital de Resolución de Conflictos (JDRC) quien es el ente competente para conocer y resolver el sumario administrativo deberá remitir la denuncia en caso de que fuera posible y la documentación habilitante a la Unidad Administrativa de Talento Humano (UATH) para que esta lo analice y emita un informe de procedencia a iniciar o no el proceso disciplinario, este informe no tiene el carácter de vinculante es decir la Junta puede o no considerarla para dictar su resolución (Ley Orgánica de Educación Intercultural, 2011).

Luego de estas diligencias tanto en el procedimiento sancionador general contemplado en el COA, como en sumario administrativo del reglamento de la LOEI en su artículo 347, la entidad pública con los elementos de convención suficientes procede a dictar el inicio del proceso en base al análisis y al estudio de los hechos efectuados en la fase de acciones previas.

Posterior a ello y de manera similar en los procedimientos administrativos referidos, se realiza la notificación al servidor público sumariado, acción en la cual se deberá adjuntar toda la documentación que consta en el expediente conformado. Esto con la finalidad que el procesado en la vía administrativa pueda conocer el motivo del por qué se le está iniciando el proceso disciplinario administrativo y de este modo pueda ejercitar su legítimo derecho a la defensa como garantía fundamental dentro del 
debido proceso, donde tendrá que dar contestación por escrito a los fundamentos de hecho y derecho que se le imputan.

Por otra parte, se puede observar algunas diferencias en la etapa de notificación y contestación entre los procedimientos administrativos pre citados, en este sentido, se advierte que el docente sumariado puede o no realizar la contestación dentro del término previsto por el RGLOEI, a más de ello tiene la posibilidad de comparecer al proceso en cualquier momento. En cuanto que, en el proceso sancionador del COA, el servidor público que no proceda a dar contestación al inicio del procedimiento sancionador corre el riesgo que la autoridad pueda elaborar un dictamen final, esto en el caso que la entidad tenga total precisión de los hechos imputados, inclusive dentro de este procedimiento se incorpora una infracción administrativa flagrante en donde se permite a la administración pública imponer sanciones en el idéntico instante del cometimiento de la infracción (Código Orgánico Administrativo, 2017, Art. 250,251,252).

En este mismo contexto, una vez concluida con la diligencia de la notificación y con la respectiva contestación o no del sumariado, se deberá providenciar la apertura período de prueba que en el caso de los docentes es de un término de 5 días hábiles, mientras tanto que en el COA se observa algunas actuaciones procedimentales distintas a lo estipulado en el RGLOEI, constituyéndose como una actividad novedosa, que se le otorga al imputado la posibilidad de reconocer libre y voluntaria su culpabilidad, situación que tiene que ejecutarse previo a que se emita la resolución correspondiente, en cuyo caso se le otorgará al procesado las excepciones estipuladas en referido Código (Código Orgánico Administrativo, 2017, Art. 253).

De igual manera consta en el artículo 255 del COA las actuaciones de introducción donde se dispone que en el término de 10 días el inculpado podrá solicitar que se practiquen diligencias $\mathrm{o}$ incorporen documentos que creyere pertinentes para descargar su responsabilidad dentro del proceso, del mismo modo, el instructor podrá solicitar y realizar cualquier actuación para recopilar elementos que permitan en lo posterior a la administración pública emitir su resolución. Del mismo modo, dentro de la etapa de prueba del sumario administrativo para docentes el artículo 
349 del reglamento a la LOEI señala que en el término de 5 días el servidor público sumariado podrá solicitar que se practiquen cuantas diligencias considere necesarias, de igual forma y en el mismo lapso de tiempo la administración pública podrá solicitar como prueba la incorporación de nueva documentación al proceso y también requerir que se practiquen diligencias para su incorporación como prueba. Al comparar estas evidencias, se puede advertir que la prueba mantiene un papel preponderante dentro del procedimiento sumario administrativo pues la misma busca la protección de un derecho que haya sido vulnerado al momento que el servidor público incurra en una falta grave en el desempeño de sus funciones ya sean estas actuaciones por acciones u omisiones, lo cual sin duda resulta en una inevitable afección directa a la parte administrada, en este caso es necesario mencionar que el juzgador habrá de adentrarse a la parte hipotética de los hechos con la finalidad de realizar una correcta valoración de la prueba, por ello deberá analizar si los supuestos presentados son de trascendental importancia para resolver el litigio puesto en su conocimiento, de ahí que deviene la importancia de que las partes procedan a entregar pruebas pertinentes, ya que ello permitirá que el juez realice su trabajo de mejor manera utilizando las herramientas que la ley y la Constitución lo permitan para determinar una resolución apegada a la verdad y la justicia (Nisimblat, 2012).

Luego de la etapa de prueba del sumario administrativo formulado en contra de los docentes, se da paso a la audiencia oral, la misma que según se estipula en el artículo 350 del RGLOEI señala que, tanto la parte solicitante del sumario y la parte sumariada comparecerán a esta diligencia con el objetivo de respaldar las pruebas que de manera previa hayan sido presentadas a su favor y contradecir las pruebas que creyeren contrarias a sus intereses.

De igual forma haciendo alusión a lo manifestado por la LOSEP y su reglamento general como norma subsidiaria a la LOEI y su reglamento en lo que respecta a la audiencia oral, en su artículo 95 inciso segundo señala que, esta diligencia corresponderá ser traducida a un acta escrita para dejar constancia de todo lo actuado y cuyo responsable será el titular de la (UATH) o su delegado quien 
suscribirá de forma conjunta con el secretario ad-hoc. Designado, dejando de forma opcional la suscripción de la misma a la parte sumariada.

Culminado la etapa de prueba el titular o delgado de la UATH remitirá al ente sancionador del distrito educativo todo el expediente, adjuntando su informe con las debidas conclusiones y recomendaciones donde se incluirá la posible sanción de ser el caso, este informe no es vinculante para que la JDRC emita su resolución administrativa final (Reglamento General Ley Orgánica de Educación Intercultural., 2012, Art. 351), de manera subsiguiente según la norma ibídem en su artículo 352 indica que, una vez que la JDRC en su calidad organismo competente que se encuentra revestido por la potestad sancionadora recibe el informe de la UATH este procedera ha emanar la respectiva resolución mediante una providencia final misma que será notificada al sumariado y que contendra si el caso lo amerita la sanción correspondiente de forma motivada. Debiendo mencionar que la pre nombrada resolución se encuentra sujeta al recurso de apelación ante el nivel zonal de educación.

\section{La vulneración del debido proceso en los sumarios administrativos instaurados en contra de los docentes del Ministerio de Educación}

Una vez que se analizaron las normas pertinentes que regulan el proceso del sumario administrativo dentro del Ministerio de Educación se debe señalar que el artículo 344 del RGLOEI, menciona que los procedimientos previstos en la LOEI y su reglamento general se deberán ejecutar en cumplimiento a lo dispuesto en el artículo 76 de la Constitución de la Republica con relación al debido proceso, en el mismo artículo en su inciso tercero de la norma infra constitucional se expone que, en ningún proceso e investigación administrativa se admitirá indefensión bajo la pena de ser declarada con la nulidad absoluta (Reglamento General Ley Orgánica de Educación Intercultural, 2012).

A pesar de que existen normas expresas dentro de la LOEI y su reglamento general con respeto al cumplimiento del debido proceso en cualquier sumario administrativo, en la práctica procedimental no se cumple con lo dispuesto, es aquí donde radica la importancia de esta investigación, ya que centra su atención en la falta de claridad y 
precisión de la manera que se deberá solicitar y evacuar la prueba dentro del procedimiento del sumario administrativo, así también se analizará la conformación del ente sancionador, en virtud de, que el mismo deberá cumplir con los preceptos legales de ser un juez natural y competente.

Así también en referencia a la falta de determinación de la forma en que se deberá actuar la prueba dentro del proceso, el artículo 349 del RGLOEI y el artículo 95 del RGLOSEP como norma subsidiaria la LOEI, refieren de manera única a que la partes pueden solicitar que se efectúen cualquier tipo de pruebas a su favor, dejando entrever una vulneración al debido proceso y a la seguridad jurídica, ya que las normas citadas no disponen de forma clara, la manera en que se deberá solicitar las pruebas dentro de un sumario administrativo, teniendo como derivación que la administración pública incurra en problemas con respectó a la idoneidad de las pruebas recabadas tanto en la etapa de acciones previas y en la etapa de prueba.

Visto de esta forma, esta problemática surgiría al momento que el juzgador proceda con la valoración de las pruebas presentadas en el proceso. En este sentido es importante referir sobre la idoneidad de las pruebas, para ello se ha hecho alusión a lo señalado por Maldonado (2019) quien indica que la prueba ilícita es toda aquella que vulnera derechos constitucionales, en síntesis, toda prueba obtenida en desapego de lo que dispone la Carta Magna será declarada nula y por consiguiente ilegal. Por otra parte, una vez que el sumariado procede a solicitar cualquier tipo de prueba, esta petición tiene que materializarse por constituirse en un derecho del procesado, por consiguiente, la administración pública no pudiere decretar ningún tipo de negativa (Pérez, 2015).

Con respecto a la falta de un ente imparcial o de un juez natural para dictar una resolución en estos tipos de procedimiento administrativos, es necesario señalar que en todo procedimiento la parte procesada tiene como derecho fundamental el ser juzgado por un juez natural, al respecto, Remón (2014) señala, que el juez natural es el operador de justicia independiente y ajeno al problema puesto en su conocimiento, además este gosara siempre de plena libertad para emitir sus resoluciones, así también de forma obligatoria éste mantendra una correcta formación profecional con vastos conocimientos de la disciplina del Derecho. 
El criterio expresado, denota aspectos fundamentales que deberan ser considerados en lo referente al concepto emanado del Juez Narural, ya que en el sumario administrativo el organismo de la JDRC según lo dispuesto en la Ley Orgánica de Educación Intercultural (2011, Art. 65), esta conformada por el Director Distrital de Educación, el Jefe de la UATH, y el Jefe de Asesoría Jurídica, mismos que también forman parte del ente sustanciador del procedimiento sancionador por motivo de pertenecer al ente administrativo del Ministerio de Educación en el nivel distritral, además se debera considerar que la Jefatura de Asesoría Jurídica y de la Unidad de Talento Humano son los unicos cargos dentro del distrito educativo que de acuerdo al perfil se exige que los servidores públicos cumplan con el debido conocimiento y manejo del campo del Derecho, lo manifestado mantiene como base el Manual de Valoración de Puestos del Ministerio de Educación.

Así también los pre nombrados funcionarios que integran la JDRC al mantener el conocimiento en la diciplina del Derecho, de forma cotidiana ortorgan asesoramiento legal a los demás servidores públicos que laboran en las diferentes unidades que conforman este organismo, acatando de esta forma las atribuciones que ellos mantiene y que están dispuestas en el (Estatuto Orgánico de Gestión Organizacional por Procesos del Ministerio de Educación , 2012).

\section{METODOLOGÍA}

La metodología de investigación jurídica aplicada en el presente artículo permitió identificar la vulneración del derecho del debido proceso en los procedimientos de sumarios administrativos sustanciados en contra de los docentes del Ministerio de Educación del Ecuador, para ello fue necesario analizar a profundidad el marco jurídico que rige a las entidades públicas del sector educativo. El desarrollo del artículo se sustentó además en la investigación documental de alcance descriptivo ya que se levantó y proceso información de la Constitución, la LOEI, el reglamento LEOI, LOSEP, Reglamento a la LOSEP, COA. La aplicación del método sistémico permitió tipificar el ordenamiento jurídico referido a los procesos de sumarios administrativos de los docentes (Mogrovejo, Erazo, Pozo Narváez, 2020). 


\section{APORTES GENERADOS.}

El debido proceso al ser considerado como un Derecho Constitucional fundamental debe encontrarse presente en todo tipo de procedimiento sea judicial y administrativo, para lograr, que las personas que se encuentran inmersas dentro de un procedimiento punitivo cuenten con una herramienta jurídica válida para hacer respetar sus derechos (Benavides, 2017).

Dentro de esta perspectiva el debido proceso contemplado en el procedimiento administrativo sancionador constituirá un derecho y una garantía para acceder de una forma directa a un mecanismo claro, imparcial y trasparente, del mismo modo el debido proceso al ser apreciado como un conjunto de derechos de mayor jerarquía estará siempre vigilante que no exista ningún tipo de vulneración hacia las personas por parte de las entidades públicas encargas de impartir justicia. Donde además los juzgadores puedan llegar a emanar una resolución o sentencia apegada mayormente a la verdad.

En el mismo contexto, se pudiera referir que el derecho a la defensa está en forma directa correlacionado con el debido proceso, y que en el territorio ecuatoriano está considerado como una garantía fundamental por medio de la cual la persona va a tener la certeza que todo organismo le otorgara un juicio justo, respetando siempre los principios y derechos que conforman a la institución jurídica del debido proceso en total concordancia y en atención a lo dispuesto en los instrumentos internacionales que contengan derechos más favorables a los seres humanos.

El proceso del sumario administrativo se encuentra contemplado en el RGLOEI desde al artículo 344 al artículo 352, en donde se explican todas las fases que contempla referido procedimiento, desde su etapa de acciones previas hasta la etapa de resolución, es este caso es necesario indicar, que el sumario administrativo instaurado en contra de los docentes de forman parte del Ministerio de Educación si bien es cierto en el artículo 344 de la norma ibídem señala, la importancia de respetar las normas constitucionales del debido proceso; en la presente investigación se observa que este precepto legal no se estaría cumpliendo con lo dispuesto en referida norma. 
En consecuencia, el aporte que otorga el presente artículo consistirá en el análisis realizado a todas las fases del procedimiento del sumario administrativo, donde se evidencio que el derecho al debido proceso con especial énfasis en la etapa de prueba y al derecho de ser juzgado por un juez natural se encuentra siendo trasgredido, en cuanto a que no se contempla normas claras que permitan a las partes procesales solicitar y evacuar pruebas dentro del proceso, así también, se demuestra que la parte administrativa requiere ejecutar actuaciones de investigación en la etapa de acciones previas, donde de manera similar, no se determina las condiciones en que se van a recabar estos elementos de convicción por la unidad de Talento Humano, los mismos que en lo posterior se convierten en pruebas en contra de la parte sumariada, y que luego en su etapa final de resolución deberán ser valoras por la JDRC.

\section{REFERENCIAS CONSULTADAS}

1. Asamblea Constituyente. (2008). Constitución de la República del Ecuador. Montecristi, Ecuador: Corporación de Estudios y Publicaciones.

2. Asamblea Nacional . (2012). Reglamento General a la Ley Orgánica de Educacíon Interculrtural . Registro Oficial Suplemento N. 754 . Quito, Ecuador: Corporación de Estudios y Publicaciones.

3. Asamblea Nacional. (2011). Ley Orgánica de Educación Intercultural . Registro Oficial Suplemento N. 417 . Quito: Corporación de Estudios y Publicaciones.

4. Bedón, N. (2016). El debido proceso en los procedimientos administrativos para el ejercicio de la potestad disciplinaria del Consejo de la Judicatura. bachelorThesis. Quito: Universidad de las Américas.

5. Benavides, M. (2017). Derecho Ecuador.com. Obtenido de (https://www.derechoecuador.com/garantia-del-debido-proceso)

6. Blanco, C. (2012). El derecho al debido proceso en la jurisprudencia de la Corte Interamericana de Derechos Humanos. Editorial Universidad del Rosario.

7. Bonilla, H. (2015). El control de convencionalidad como instrumento de diálogo jurisprudencial en América Latina. Revista Jurídica IUS Doctrina. 
8. Cardona, E. (1994). El principio de la iguldad material en la jurisprudencia del tribunal constitucional . Revista de los Estudios Politicos , 266.

9. Código Orgánico Administrativo. (2017). Registro Oficial Suplemento N. 31. Quito, Ecuador : Corporación de Estudios y Publicaciones.

10. Código Orgánico Administrativo. (2017). Código Orgánico Administrativo. Registro Oficial Suplemento N. 31. Quito, Ecuador : Corporación de Estudios y Publicaciones.

11. Espinoza, W. (2000). El debido proceso en la Constitución. Usfq.edu.ec, 35.

12. Estatuto Orgánico de Gestión Organizacional por Procesos del Ministerio de Educación . (2012). Acuerdo Ministerial 20. Registro Oficial Suplemento N. 259. Quito , Ecuador : Corporación de Estudios y Publicaciones.

13. Gómez, S. (2015). El sumario administrativo y la prescripción ante la seguridad jurídica y los derechos constitucionales. Master's thesis, 40.

14. González, M. (2006). Estudios juridicos en homenaje a Marta Morineau. En N. G. Martin, Estudios juridicos en homenaje a Marta Morineau (pág. 345). Mexico: Univercidad Nacional Autonoma de Mexico, Instituto de investigacion juridica.

15.Grijalva, A. (2012). Consticionalismo en el Ecuador. Quito: Corte Constitcucional para el Periodo de Transición.

16. Guzmán Chávez, M. (2019). El principio constitucional de la tutela judicial efectiva vulnerado por la acción de nulidad de sentencias. IUSTITIA SOCIALIS, 4(7), 135-145. doi:http://dx.doi.org/10.35381/racji.v4i7.366

17. Ley Orgánica de Educación Intercultural . (2011). Registro Oficial Suplemento N. 417 . Quito: Corporación de Estudios y Publicaciones.

18. Ley Orgánica de Educación Intercultural. (2011). Registro Oficial Suplemento N. 417. Quito: Corporación de Estudios y Publicaciones.

19. Ley Orgánica de Educación Intercultural. (2011). Registro Oficial Suplemento N. 417. Quito, Ecuador: Corporación de Estudios y Publicaciones.

20. Ley Orgánica de Educación Intercultural. (2011). Ley Orgánica de Educación Intercultural. Quito, Ecuador: Corporación de Estudios y Publicaciones.

21. Ley Orgánica de Servicio Público. (2010). Registro Oficial Suplemento N. 294. Quito: Corporación de Estudios y Publicaciones.

22. Maldonado, A. (2019). Las interceptaciones de comunicaciones como medio de prueba dentro del proceso penal y la violación al derecho constitucional de intimidad. Master's thesis.

23. Mogrovejo Gavilanes, A. R., Erazo Álvarez, J. C., Pozo Cabrera, E. E., \& Narváez Zurita, C. I. (2020). Aplicación del Principio de proporcionalidad en la 
Jurisprudencia de la Corte Constitucional del Ecuador. Iustitia Socialis, 110. doi: http://dx.doi.org/10.35381/racji.v5i8.563

24. Nisimblat, N. (2012). Derecho procesal constitucional y derecho probatorio constitucional en Colombia. Centro de estudios constitucionales de Chile universidad de Talca.

25. Nogueira, H. (2003). Los derechos esenciales o humanos contenidos en los tratados internacionales y su ubicación en el ordenamiento jurídico nacional: doctrina y jurisprudencia. lus et Praxis.

26. Pérez, J. (2015). Derecho constitucional a la prueba judicial. Una aproximación. Estudios de derechos.

27. Pertile, F. (2005). El Sumario Administrativo. Bogota: Advocatus Ediciones.

28. Reglamento General Ley Orgánica de Educación Intercultural. (2012). Reglamento General Ley Orgánica de Educación Intercultural. Registro Oficial Suplemento N. 754. Quito, Ecuador: Corporación de Estudios y Publicaciones.

29. Reglamento General Ley Orgánica de Educación Intercultural. (2012). Registro Oficial Suplemento N. 754 . Quito, Ecuador: Corporación de Estudios y Publicaciones.

30. Remón, F. (2014). El derecho al juez natural-como derecho humano-y los tribunales militares en Colombia. Eunomia.

31. Rodríguez, P. (2010). El Debido Proceso, sus origenes, su evolucion y su reconcimeinto en el nuevo sitema de justicia penal en Mexico. Alter.

32. Rojas, F. (2011). El debido procedimiento administrativo. Revista de la Facultad de Derecho.

33. Ruocco, G. (2013). El principio del debido proceso en la vía administrativa. Direitos Fundamentais e Democracia, 5.

34. Sanabria, D. (2017). La prueba nueva en el código orgánico general de procesos y su vulneración al derecho a la legítima defensa y contradicción consagrados en la constitución de la República del Ecuador. Bachelor's thesis.

35. Sarango, H. (2008). El debido Proceso y el principio de motivacion de las resoluciones/sentencias judiciales. Univercidad Andina Simon Bolivar, 16-18.

36. Secretaría Técnica Jurisdiccional. (2016). Desarrollo jurisprudencial de la primera Corte Constitucional. Quito: Centro de Estudios y Difusión.

37. Talavera, P. (2009). La Prueba en el Nuevo Proceso Penal: Manual del Derecho Probatorio y de la valorización de las pruebas en el Proceso Penal Común. Lima. 
38. Velásquez, B. (2017). El procedimiento sumario administrativo a la luz del debido proceso. Quito: Corporacion Editorial Nacional.

(C2020 por los autores. Este artículo es de acceso abierto y distribuido según los términos y condiciones de la licencia Creative Commons Atribución-NoComercial-Compartirlgual 4.0 Internacional (CC BY-NC-SA 4.0)

(https://creativecommons.org/licenses/by-nc-sa/4.0/). 